\title{
AEROBIC CAPACITY OF JUDO PLAYERS SCALED FOR DIFFERENCES IN BODY SIZE
}

\author{
Diana Dimitrova, Lubomir Mladenov, Anna Nikolova
}

National Sports Academy "Vassil Levski", Sofia, Bulgaria

\begin{abstract}
The aerobic capacity is considered to be a prerequisite for high training and competitive performance in judo. However, it is not clear how the differences in the body composition of judokas affect their aerobic performance. The present study was aimed at comparing the body composition variables and aerobic capacity among judo players from different weight categories and examining the best method for scaling the $\mathrm{VO}_{2}$ max for differences in body mass. The subjects were 109 male and 108 female judokas 15-26 years old, grouped in three weight categories for each sex. Percentage of body fat $(\% B F)$ was predicted by skinfold equations. Fat mass, fat-free mass (FFM) and BMI were also calculated. The maximal oxygen uptake ( $\mathrm{VO}_{2}$ max) was measured during a graded maximal bicycle ergometer test. The correlations between $\mathrm{VO}_{2}$ max, normalized by different methods, and body size variables were tested by Pearson's productmoment correlations.

The \%BF and body composition variables significantly differed among weight categories and were with the highest values in the heaviest athletes. The average $\mathrm{VO}_{2}$ max. $\mathrm{BM}^{-1}$ of the entire groups of male and female judokas were respectively $48.4 \pm 4.7 \mathrm{ml} . \mathrm{kg}^{-1} . \mathrm{min}^{-1}$ and $39.7 \pm 4.0$ $m l . \mathrm{kg}^{-1} . \mathrm{min}^{-1}$. The lightweight classes demonstrated the highest relative to BMvalues of $\dot{V} \mathrm{O}_{2}$ max. When $\mathrm{VO}_{2}$ max was adjusted to BM with derived allometric exponents $(0.77$ for males and 0.69 for females) the results for the three weight categories of male and female judokas were similar, regardless of the differences in their body composition.

The interpretation of the between-weight categories differences in aerobic capacity in judo$\mathrm{kas}$ is dependent on the method of expression of $\mathrm{VO}_{2}$ max. The $\mathrm{VO}_{2}$ max, normalized for $\mathrm{BM}$ or $F F M$, did not remove the effect of body size and still correlated with body composition variables in both sexes. The power function expression of $\mathrm{VO}_{2}$ max produced size-free variables, which did not correlate with body size in judokas.
\end{abstract}

Key words: judo, aerobic capacity, $\mathrm{VO}_{2}$ max, body composition, allometric scaling

\section{INTRODUCTION}

Judo is one of the most popular combat sports in the world that became an official Olympic sport in 1972 for men and in 1992 for women.

The competitive success in judo requires not only tactical skills, but also complex motor skills - strength, speed, flexibility, agility, dynamic and static balance, coordination, explosive power (Callister et al., 1991; Little, 1991;
Sterkowicz-Przybycień, 2011).

Judo match has a dynamic intermittent character and duration of up to 5 min that can be extended at the referee's decision for another 3 minutes. The contest is characterized by the repetition of brief combat periods, when the contestants perform attacks with maximal or supramaximal intensity, alternating with periods of breaks that are effortless. Franchini et al. (2013) reviewed the studies perform- 
ing time-motion analysis of judo matches and found that the periods of efforts vary from 10 secs to 63 secs and pause periods vary from 1 sec to 22 secs. The power attacks of judokas are highly dependent on anaerobic metabolism. Although no direct method of determining anaerobic performance currently exists, variety of anaerobic tests have been used for assessment of upper and lower body part of judokas (Borkowsky et al., 2001; Ali et al., 2010; Franchini at al., 2005, Franchini, et al., 2011b). Accordingly, high values of the peak and mean power during Wingate test, especially in the upper body, have been documented in judo players from different national teams (Franchini et al., 2005; Kim et al., 2011, Thomas et al., 1989). Because the duration of attack periods is about twice as long as the effortless periods, it is generally considered that judo is a primary anaerobic sport. However, the effective fight carried out by judo players depends on the aerobic energy systems as well. The aerobic metabolism contributes to faster restoration of high-energy substrates and delayed accumulation of metabolites in the periods of breaks between attacks as well as for the faster recovery from the consecutive matches (Franchini, et al., 2009; Franchini, et al., 2011a, b). During the tournament, the number of matches performed by the elite contestants may reach 6 or 8 on a single day. Therefore, the aerobic capacity is considered as a prerequisite for high training and competitive performance of judo contestants (Kubo et al., 2006, Thomas et al., 1989). The most widely used aerobic capacity indicator is the maximal oxygen uptake $\left(\mathrm{VO}_{2} \max \right)$, which is defined as the highest rate of oxygen consumption attainable during maximal or exhaustive exercise. The $\mathrm{VO}_{2} \max$ of athletes practicing judo has been subject to research with regards to age, sex, competitive level, etc. (Callister et al., 1991; Borkowsky et al., 2001; Nikolova, Dimitrova, 2018; Thomas et al.,
1989). However, the mean values of $\dot{\mathrm{V}} \mathrm{O}_{2} \max$ from different nationalities ranged widely between about 45 and $63 \mathrm{ml} \cdot \mathrm{kg}^{-1} \cdot \mathrm{min}^{-1}$ in males, and between 40 and $52 \mathrm{ml} \cdot \mathrm{kg}^{-1} \cdot \mathrm{min}^{-1}$ in females (Franchini, et al., 2011a). Apart from genetic factors and a different level of cardiorespiratory fitness of the athletes, the large variability of reported data is partly due to the different research methodologies - protocols, equipment, and exercise modes.

On the other hand, body size and composition are recognized as factors, which significantly influence the aerobic capacity. Judo is a weight-classified sport and therefore the body size of the contestants varies widely. The athletes from both sexes compete in seven weight classes. For male competitors the weight divisions are $<60 \mathrm{~kg}, 66, \mathrm{~kg}, 73 \mathrm{~kg}, 81 \mathrm{~kg}, 90 \mathrm{~kg}$, $100 \mathrm{~kg}$, and $>100 \mathrm{~kg}$; and for female athletes the respective weight classes are $<48 \mathrm{~kg}, 52$, $\mathrm{kg}, 57 \mathrm{~kg}, 63 \mathrm{~kg}, 70 \mathrm{~kg}, 78 \mathrm{~kg}$, and $>78 \mathrm{~kg}$. Although, judokas attempt to minimize their body weight and body fats, studies have indicated an increase in body fat percentage from lightweight to heavy-weight category (Callister et al., 1991; Thomas et al., 1989; Borkowski et al., 2001). Comparing body size and composition of judokas with different athletic achievements, studies have generally shown that athletes with lower percentage of body fat are more successful (Callister et al., 1991; Kubo et al., 2006; Nikolova, Dimitrova, 2018).

The negative influence of body fat on aerobic performance has also been documented (Franchini et al., 2007). However, probably due to relatively small studied samples, the publications to date have not presented a comprehensive analysis of body composition influence on the aerobic performance of judo contestants with respect to the weight categories.

In addition, in most of the studies, the $\mathrm{VO}_{2}$ max is traditionally expressed as scaled by body weight $\left(\mathrm{ml} . \mathrm{min}^{-1} \cdot \mathrm{kg}^{-1}\right)$ to compare values 
between athletes of different sizes. This socalled simple ratio standard is based on the assumption of a linear relationship between the aerobic capacity and body size, which is rarely satisfied (Katch, Katch, 1974). However, this manner of adjustment has been criticized, because it does not eliminate the effect of the body size, and the normalized indices of $\mathrm{VO}_{2}$ max could yet display a residual correlation with BM (Maciejczyk et al., 2014, Nevill, 1994, Toth et al., 1994, Heil, 1997).

One of the alternative methods of scaling is the allometric or power function modelling, which is based on the theoretical presumption of biological similarity. The power function expresses the relationship between $\mathrm{VO}_{2} \max$ and $\mathrm{BM}$ by the equation:

\section{$\mathrm{VO}_{2} \max =a B M^{b}$,}

where $a$ is a proportionality constant and $b$ is the scaling exponent.

It is assumed that allometric scaling removes the effects of BM and body composition when we compare groups with different body sizes (Chia, Aziz, 2008). Although some authors used theoretical exponents (most commonly 0.67 and 0.75 ) that are predicted by dimensional theory, it is recommended for sports populations to derive sample-specific scaling factors (Nevill et al., 1992, 2003).

Because judo is a weight category sport, normalizing the $\mathrm{VO}_{2}$ max to body mass is important for understanding the physiological response to training in athletes of different body size. The use of appropriate techniques for scaling the $\mathrm{VO}_{2}$ max provides options to clarify the between-weight category differences in aerobic capacity of judo athletes. Our hypothesis is that neither the absolute nor the simple ratio-standard expression of $\mathrm{VO}_{2} \max$ remove the influence of body size on $\mathrm{VO}_{2}$ max and they are not appropriate for evaluation of the aerobic performance of judo players.

Therefore, the present study was aimed at
1) comparing the body composition variables and aerobic capacity among competitive judo players from different weight categories and 2) examining the best method for scaling the $\mathrm{VO}_{2}$ max for differences in body size.

\section{METHODOLOGY}

The investigation was performed in accordance with the ethical standards of the Helsinki Declaration. All research procedures, including testing protocol, received approval from the Ethical board of the National Sports Academy. The athletes and their parents were informed about the objective and design of the study and provided their written consent for participating in the study.

\section{Participants}

Two hundred and seventeen (108 females and 109 males) judo athletes participated in this study. The age of athletes was between 15 and 26 years, mean age 19.6 \pm 3.4 . Study participants had to meet the following criteria: to be well-trained judokas with training experience of at least 8 years and to be competitors licensed by the Bulgarian Judo Association. They were evaluated during pre-participation physical and medical examinations in 2016-2018. The main exclusion criterion was the presence of contraindications to perform a maximal physical effort test (Fletcher et al., 2013).

For the purpose of the analyses, athletes were grouped with respect of their actual weight measured during the study. For male judokas the groups were lightweight category $(-60 \mathrm{~kg},-65 \mathrm{~kg},-70 \mathrm{~kg})(\mathrm{n}=70)$, middleweight category $(-81 \mathrm{~kg}, 90 \mathrm{~kg})(\mathrm{n}=27)$ and heavyweight category (-100 kg and over $100 \mathrm{~kg}$ ) $(n=12)$. The respective groups for female judokas was lightweight category $(-48 \mathrm{~kg},-52 \mathrm{~kg}$, $-57 \mathrm{~kg})(\mathrm{n}=38)$, middleweight category ( 63 $\mathrm{kg},-70 \mathrm{~kg})(\mathrm{n}=50)$ and heavyweight category $(-78 \mathrm{~kg}$ and over $78 \mathrm{~kg})(\mathrm{n}=20)$. 


\section{Anthropometric measurements}

All athletes underwent an anthropometric assessment by the same experienced investigator who followed the international standards for anthropometric assessment, published by the International Society for the Advancement of Kinanthropometry (ISAK) (Marfell-Jones et al.,2006). The equipment used to obtain anthropometric measures was calibrated at the beginning and end of each examining day. Participants were wearing light clothing and no shoes during measurements. Body mass (BM) was measured with a calibrated electronic weighing scale with precision of 0.1 $\mathrm{kg}$ and height were measured using a GPM anthropometer (Switzerland) with accuracy of $0.1 \mathrm{~cm}$. Four skinfold thickness measurements (triceps, subscapular, supraspinal, and front thigh) were taken with a Lange Skinfold Caliper (Cambridge Scientific, Cambridge, MD, USA) to the nearest $0.1 \mathrm{~mm}$. Duplicate readings were taken at each site, and the average value was used for the analysis. If the two readings differed by more than $2 \mathrm{~mm}$, a third one was taken, and the closest two were averaged.

\section{Body composition estimation}

Anthropometric measures were used for the prediction of body composition variables. Body density was predicted using 4 skinfolds equations of Jackson\&Pollock (Jackson, Pollock, 1978, 1980, 1985). The percentage of body fat $(\% \mathrm{BF})$ was calculated with Siri equation (Siri, 1961).

Fat mass (FM) and fat-free mass (FFM) were calculated using the respective formulas:

$$
\begin{aligned}
& F M=(B W x \% B F) / 100(\mathrm{~kg}) \\
& F F M=B W-F M(\mathrm{~kg})
\end{aligned}
$$

Body mass index (BMI) was calculated as body mass in kilograms divided by height in meters squared $\left(\mathrm{kg} \cdot \mathrm{m}^{-2}\right)$.

\section{Maximal oxygen uptake test ( $\mathrm{O}_{2}$ max)}

The tests were preceded by a routine clinical examination. The oxygen uptake $\left(\mathrm{VO}_{2} \mathrm{max}\right)$ was measured during a graded maximal aerobic power test performed on a bicycle ergometer Ergometrics er800s (Ergoline, Germany). The test was performed after a 15-min warmup. Initially, the workload was set at $60 \mathrm{~W}$ and every $90 \mathrm{sec}$ the workload was increased by 30 W until the subjects reached a volitional exhaustion or were unable to maintain the pedal cadence. During the test, the pedaling rate was kept constant at $80 \mathrm{rpm}$.

The attainment of $\mathrm{VO}_{2}$ max was validated if at least two of the following criteria were met: (1) reaching a plateau in $\mathrm{VO}_{2}$ max with an increase of the power output; (2) a respiratory exchange ratio $\geq 1.1$; (3) the heart rate approaches $( \pm 10 \%)$ the age-predicted maximal heart rate (220-ages) and (4) or volitional fatigue.

Maximal oxygen uptake was defined as the maximal attained $\mathrm{VO}_{2}$ at the end of the exercise period in which the subject reached exhaustion. Gas exchange and ventilatory variables were measured continuously during the gas exchange tests, breath by breath, using an open-circuit spirometry procedure on a Quark CPET Metabolic cart (Cosmed, Italy).

Before each test, the gas analyzers were calibrated with the use of gases of known concentration of carbon dioxide and oxygen balanced with nitrogen, and the flow meter was calibrated with a 3-L syringe. Heart rate was continuously recorded at rest and during the graded exercise testing with an integrated 12lead ECG (Quark C12x, Cosmed, Italy).

All tests were performed at the same laboratory in the same conditions.

\section{Statistical analysis}

All analyses of data were made with the Statistical Package for the Social Sciences (SPSS), version 23 for Windows (Inc., Chicago, IL, 
USA). The statistical significance was set at $p \leq 0.05$ and the data were described as mean \pm standard deviation. We applied the Shapiro-Wilk test for assessing the normality of data. The data were statistically tested for heteroscedasticity. A one-way ANOVA nalysis was used for evaluation of the differences between groups. Next, post hoc comparisons were conducted with the Tukey's HSD test to determine the significance of between-weight categories differences.

Pearson's product moment analysis was applied on natural log-transformed data for $\mathrm{VO}_{2} \max \left(\mathrm{ml} \cdot \mathrm{min}^{-1}\right), \mathrm{BM}(\mathrm{kg})$ and height $(\mathrm{cm})$.

The allometric analysis, that was applied to the entire group for each sex, was preceded by statistical testing the appropriateness of the model. Body mass and $\mathrm{VO}_{2} \max$ were natural log-transformed and linear regression was used to find the scaling factors for males and females. The sex-specific allometric exponents were determined from the following logarithmic equation:

$\ln \left(\mathrm{VO}_{2} \max \right)=\ln (\mathrm{a})+\mathrm{b} x \ln (\mathrm{BM})$, where $\ln \left(\mathrm{VO}_{2} \max \right)$ was the natural logarithm of maximal oxygen uptake in $\mathrm{ml} \cdot \mathrm{min}^{-1}, \ln (\mathrm{BM})$ was the log-transformed data of BM (kg), $\ln (\mathrm{a})$ - the intercept, $\mathrm{b}$ - the body mass exponent (Nevill et al., 1992).

The normality of log-linear model residuals was tested also with Shapiro-Wilk test.

Pearson's product-moment correlation coefficients were used to determine the relationship between the absolute, relative to BM and FFM, and expressed as power function ratio values of $\mathrm{VO}_{2} \max$ and body composition indices.

\section{RESULTS}

Table 1 summarizes the physical characteristics, body composition variables and aerobic capacity as well as ANOVA results for between-weight category differences in male and female judo players. The mean age and training experience of the studied groups in both male and female judo players were similar.

Table 1. Characteristics, body composition and aerobic capacity in judo players

\begin{tabular}{|c|c|c|c|c|c|c|c|}
\hline \multirow[t]{3}{*}{ Group / Variable } & $\begin{array}{l}\text { Entire } \\
\text { group }\end{array}$ & $\begin{array}{c}\text { Light } \\
\text { weight cate- } \\
\text { gory (1) }\end{array}$ & $\begin{array}{c}\text { Middle } \\
\text { weight cat- } \\
\text { egory ( } 2 \text { ) }\end{array}$ & $\begin{array}{c}\text { Heavy } \\
\text { weight cat- } \\
\text { egory (3) }\end{array}$ & \multicolumn{3}{|c|}{$\begin{array}{c}\text { Mean difference } \\
\text { between categories }\end{array}$} \\
\hline & \multicolumn{7}{|c|}{ Male judokas } \\
\hline & $(n=109)$ & $(\mathrm{n}=70)$ & $(\mathbf{n}=\mathbf{2 7})$ & $(n=12)$ & (2)-(1) & (3)-(2) & (3)-(1) \\
\hline Age (yrs.) & $19.6 \pm 3.4$ & $19.7 \pm 2.7$ & $19.3 \pm 5.2$ & $19.3 \pm 1.1$ & -0.4 & -0.1 & -0.5 \\
\hline $\begin{array}{c}\text { Training } \\
\text { experience (yrs.) }\end{array}$ & $10.40 \pm 4.1$ & $10.56 \pm 3.7$ & $10.41 \pm 4.2$ & $9.82 \pm 1.2$ & -0.2 & -0.6 & -0.7 \\
\hline Height (cm) & $170.2 \pm 8.3$ & $165.92 \pm 4.5$ & $173.9 \pm 6.1$ & $186.8 \pm 2.5$ & $8.0^{*}$ & $12.8 *$ & $20.9 *$ \\
\hline Body mass (kg) & $71.2 \pm 13.5$ & $63.39 \pm 6.4$ & $78.1 \pm 3.6$ & $101.2 \pm 4.6$ & $14.8 *$ & $23.1^{*}$ & $37.8 *$ \\
\hline$\% \mathrm{BF}$ & $10.6 \pm 2.2$ & $9.94 \pm 1.8$ & $11.0 \pm 2.1$ & $13.6 \pm 1.9$ & $1.1^{*}$ & $2.6^{*}$ & $3.7^{*}$ \\
\hline FM (kg) & $7.7 \pm 2.8$ & $6.37 \pm 1.6$ & $8.6 \pm 1.6$ & $13.8 \pm 2.2$ & $2.2^{*}$ & $5.2^{*}$ & $7.4^{*}$ \\
\hline FFM (kg) & $63.5 \pm 11.1$ & $57.02 \pm 5.2$ & $69.5 \pm 3.9$ & $87.4 \pm 3.9$ & $12.5^{*}$ & $17.9 *$ & $30.4^{*}$ \\
\hline BMI (kg.m-2) & $24.38 \pm 2.8$ & $23.01 \pm 2.0$ & $25.88 \pm 1.5$ & $29.03 \pm 1.7$ & $2.9^{*}$ & $3.2^{*}$ & $6.0^{*}$ \\
\hline $\mathrm{VO}_{2} \max \left(\mathrm{L} \cdot \mathrm{min}^{-1}\right)$ & $3.41 \pm 0.5$ & $3.14 \pm 0.41$ & $3.74 \pm 0.32$ & $4.30 \pm 0.28$ & $0.6^{*}$ & $0.6^{*}$ & $1.2^{*}$ \\
\hline $\begin{array}{c}\mathrm{VO}_{2} \mathrm{max} / \mathrm{BM} \\
\left(\mathrm{ml} \mathrm{kg}^{-1} \cdot \mathrm{min}^{-1}\right)\end{array}$ & $48.4 \pm 4.7$ & $49.6 \pm 4.5$ & $46.9 \pm 3.9$ & $42.6 \pm 2.6$ & $-2.6^{*}$ & $-4.4^{*}$ & $-7.0^{*}$ \\
\hline $\begin{array}{l}\mathrm{VO}_{2} \mathrm{max} / \mathrm{FFM} \\
\left(\mathrm{ml}^{\prime} \mathrm{kg}^{-1} \cdot \mathrm{min}^{-1}\right)\end{array}$ & $53.6 \pm 7.2$ & $55.0 \pm 4.9$ & $51.8 \pm 3.3$ & $49.2 \pm 2.5$ & $-3.2 *$ & $-2.6^{*}$ & $-5.8^{*}$ \\
\hline 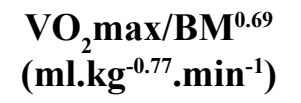 & $127.7 \pm 16.6$ & $128.6 \pm 11.8$ & $125.7 \pm 27.1$ & $123.0 \pm 7.3$ & 2.9 & 2.7 & 5.5 \\
\hline
\end{tabular}




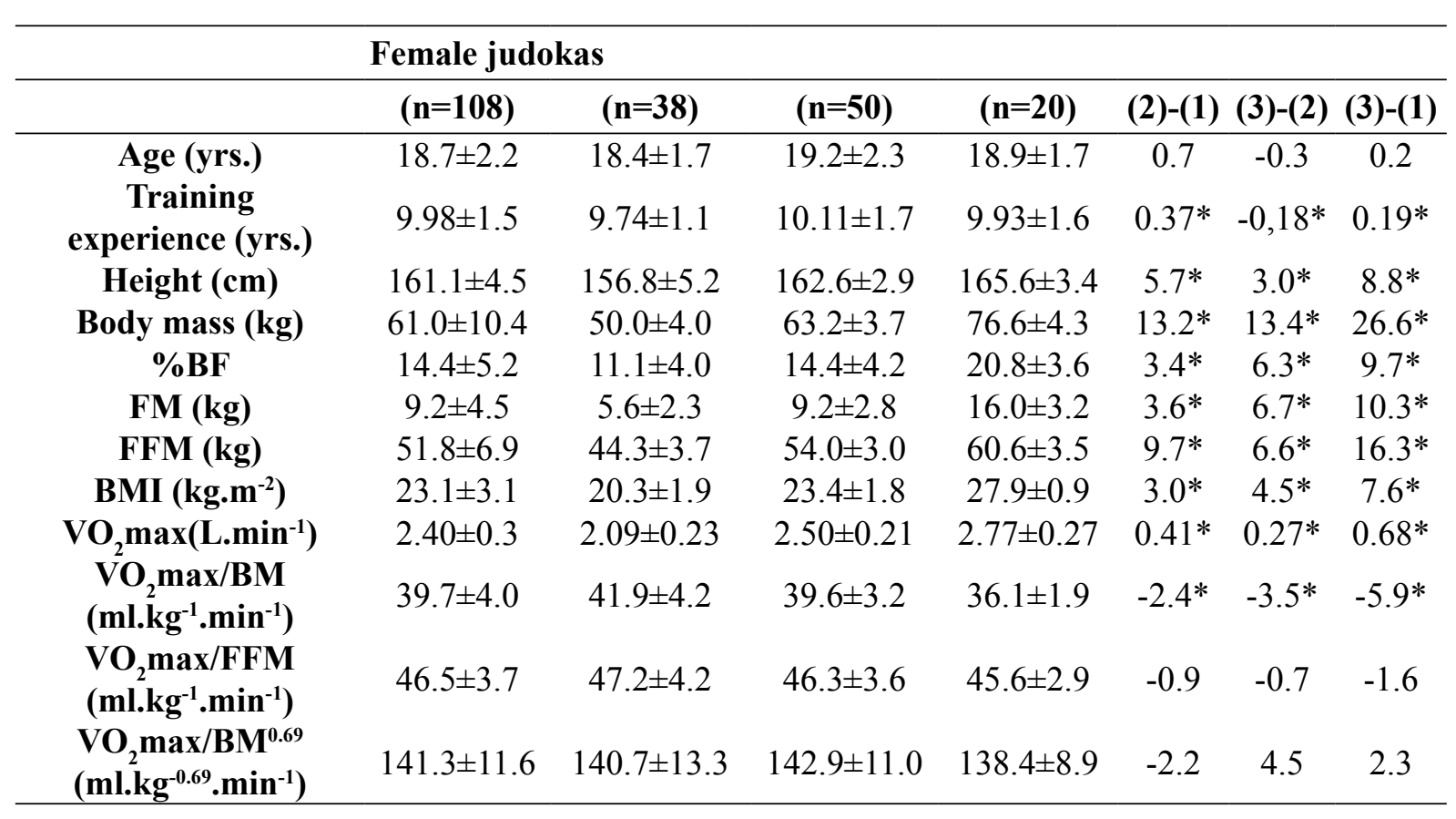

Note: The values are mean $\pm S D, B M$ - body mass, \%BF-percent body fat, FM - fat mass, $F F M$ - fat-free mass, BMI - Body mass index, $\mathrm{VO}_{2}$ max - maximal oxygen uptake *ANOVA $p<0.05$

\section{Differences in body composition between weight categories}

The results from morphological assessment showed that the anthropometric and body composition variables increased in the heavier weight divisions in both sexes and all differences between the weight groups were significant $(p<0.05)$. The male and female athletes in the heavyweight class exhibited the highest average values of the height, weight, and Body mass index. The average values of body fat percentage also showed an increase with the weight category. The percentage of BF was $9.94 \pm 1.76$ for the lightweight category, $11.02 \pm 2.07$ for the middleweight category and $13.60 \pm 1.87$ for the heavyweight category of male judokas. For female athletes $\% \mathrm{BF}$ of the corresponding groups the figures were respectively $11.08 \pm 3.99$, $14.43 \pm 4.15$ and $20.77 \pm 3.56$. The mean difference in \%BF between the heavyweight and lightweight divisions of judokas was $3.66 \%$ for the males and $9.69 \%$ for the females.

In addition, the derived variables such as fat mass and fat-free mass also increased with weight category and all differences among the groups in both sexes were significant $(p<0.05)$.

Based on the BMI the male judokas in the middleweight category, and the athletes from both sexes in the heavyweight category, were classified as over weighted (BMI $\geq 25 \mathrm{~kg} \cdot \mathrm{m}^{-2}$ ). For the other weight categories of judo players, the BMI fell into the normal recommended by WHO range.

\section{Allometric modelling}

The results from Pearson product moment analysis indicated stronger relationship between $\mathrm{VO}_{2} \max \left(\mathrm{ml} \cdot \mathrm{min}^{-1}\right)$ and $\mathrm{BM}(\mathrm{kg})$ for both sexes $(r=0.83$ for males and 0.85 for females) than between $\mathrm{VO}_{2} \max \left(\mathrm{ml} \cdot \mathrm{min}^{-1}\right)$ and height $(\mathrm{cm})(r=0.58$ for males and $r=0.61$ for females). Therefore, in the subsequent allometric procedures we used BM as a better predictor for $\ln \left(\mathrm{VO}_{2} \max \right)$. After natural log-transformation of $\mathrm{VO}_{2}$ max and $\mathrm{BM}$, sex-specific mass exponents were derived. 
The resulted regression equations were as followed:

$$
\mathrm{y}(\text { males })=4.85+0.77 \mathrm{x},
$$

and

$\mathrm{y}($ females $)=4.95+0.69 \mathrm{x}$, where $y$ is the $\mathrm{VO}_{2}$ max and $x$ is the $\mathrm{BM}$.
The scaling factor was found to be 0.77 (95\% CI: $0.68-0.86, p<0.0001)$ for male judo players and 0.69 (95\% CI: $0.60-0.78$, $p<0.0001)$ for female judokas and the difference between them was significant $(p<0.0001)$ (Figure 1).

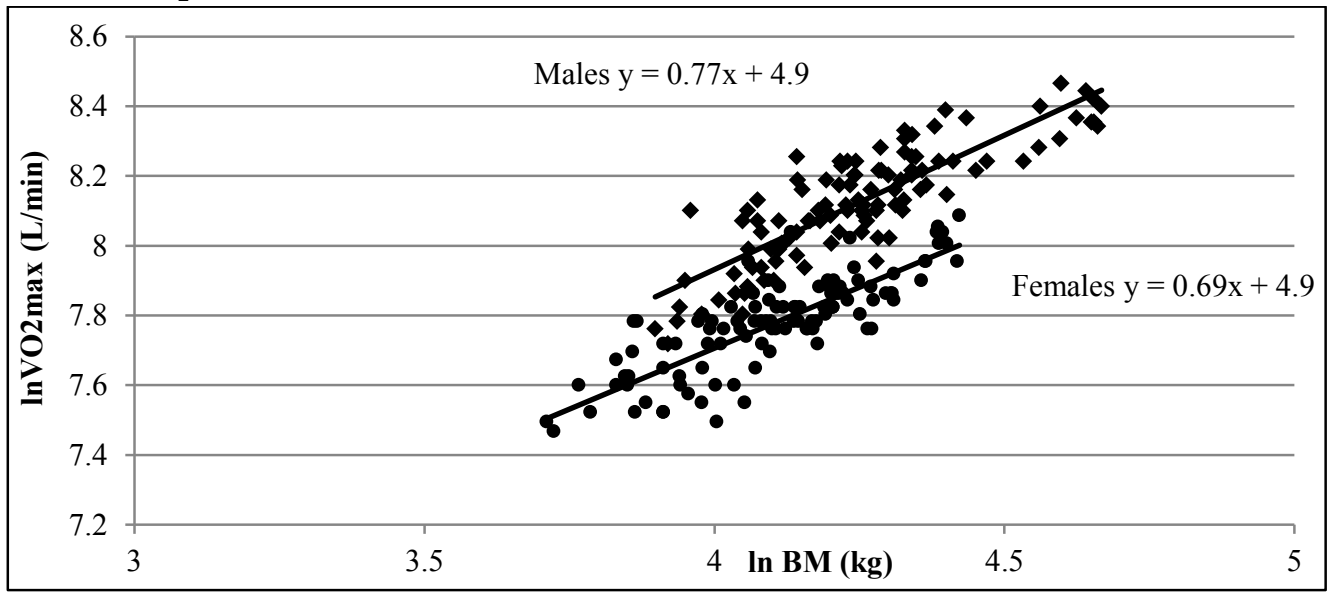

Figure 1. Linear regression model constructed using $\ln \left(V_{2} \mathrm{~m}_{2} \mathrm{max}\right)$ as the dependent and $\ln$ (body mass) as independent variables in male and female judo players for deriving the power function scaling factors.

The analysis confirmed the normal distribution of the residuals for the log-linear regression using body mass, and that the residuals were homoscedastic.

\section{Differences in aerobic capacity between weight categories}

The results from the bicycle ergometric testing of the aerobic capacity indicated that the greatest mean value of $\mathrm{VO}_{2}$ max expressed in absolute units $\left(\mathrm{L} \cdot \mathrm{min}^{-1}\right)$ was demonstrated by the male and female judokas in heavyweight category, followed by the middleweight and lightweight category (Table 1). As it can be expected, the relative to BM values of $\mathrm{VO}_{2}$ max were highest in the lightweight category in both sexes $\left(49.6 \pm 4.5 \mathrm{ml} \cdot \mathrm{kg}^{-1} \cdot \mathrm{min}^{-1}\right.$ for males and $41.9 \pm 4.2 \mathrm{ml} \mathrm{kg}^{-1} \cdot \mathrm{min}^{-1}$ for females). The values of $\mathrm{VO}_{2} \mathrm{max} / \mathrm{kg}$ were significantly lower (respectively, $47.9 \pm 3.9 \mathrm{ml} \cdot \mathrm{kg}^{-1} \cdot \mathrm{min}^{-1}$ and $39.6 \pm 3.2 \mathrm{ml} . \mathrm{kg}^{-1} \cdot \mathrm{min}^{-1}$ ) for middleweight athletes. The lowest values in $\mathrm{VO}_{2} \mathrm{max} / \mathrm{kg}$ were documented in heavyweight judokas $(42.6 \pm 2.6$ $\mathrm{ml} \cdot \mathrm{kg}^{-1} \cdot \mathrm{min}^{-1}$ and $\left.36.1 \pm 1.9 \mathrm{ml} \cdot \mathrm{kg}^{-1} \cdot \mathrm{min}^{-1}\right)$. All differences between the weight groups in both sexes were significant $(p<0.05)$.

When expressed $\mathrm{VO}_{2}$ max relative to FFM, the significant differences between the weight classes in the male judo players remained, and the lightweight athletes demonstrated the highest values. However, significant differences in the $\mathrm{VO}_{2} \max / \mathrm{FFM}$ between the groups were not observed $(p<0.05)$ in the female judokas.

The expression of $\mathrm{VO}_{2}$ max as a power function ratio used $\mathrm{BM}$ raised to the experimentally derived allometric exponents as a denominator. As a result, significant differences in the aerobic capacity between weight classes in male and female judo players were not observed (Table 1).

\section{Correlations between body composition} and aerobic capacity

Pearson product-moment correlations were run to determine the relationship between the absolute and normalized to the body mass and fat-free mass values of $\mathrm{VO}_{2} \max$ (Table 2). 
Table 2. Pearson's $r$ correlation coefficients ( $r$ ) for the association between $\mathrm{VO}_{2}$ max and body size variables

\begin{tabular}{|c|c|c|c|c|c|}
\hline Variab & & $\mathrm{VO}_{2} \max$ & $\mathrm{VO}_{2} \max / \mathrm{BM}$ & $\mathrm{VO}_{2} \max / \mathrm{FFM}$ & $\mathrm{VO}_{2} \max / \mathbf{B M}^{-0.77}$ \\
\hline BM & \multirow{6}{*}{ 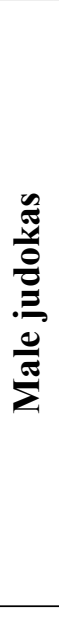 } & $\begin{array}{l}0.85(\mathrm{CI}: 0.78 \text { to } \\
0.89) \mathrm{p}=0.02\end{array}$ & $\begin{array}{l}-0.45(\mathrm{CI}:-0.59 \text { to } \\
-0.28) \mathrm{p}<.0001\end{array}$ & $\begin{array}{l}-0.25(\mathrm{CI}:-0.42 \text { to } \\
-0.07) \mathrm{p}=0.009\end{array}$ & $\begin{array}{c}-0.04 \text { (CI: }-0.23 \text { to } 0.15) \\
\mathrm{p}=0.681^{*}\end{array}$ \\
\hline$\% \mathrm{BF}$ & & $\begin{array}{l}0.50(\mathrm{CI}: 0.34 \text { to } \\
0.63) \mathrm{p}<.0001\end{array}$ & $\begin{array}{l}-0.32(\mathrm{CI}:-0.48 \text { to } \\
-0.14) \mathrm{p}=0.008\end{array}$ & $\begin{array}{c}-0.008 \text { (CI:- } 0.20 \text { to } \\
0.18) \mathrm{p}=0.934^{*}\end{array}$ & $\begin{array}{c}0.07 \text { (CI:-0.31 to }-0.18 \text { ) } \\
\mathrm{p}=0.472^{*}\end{array}$ \\
\hline FFM & & $\begin{array}{l}0.85(\mathrm{CI}: 0.79 \text { to } \\
0.89) \mathrm{p}<.0001\end{array}$ & $\begin{array}{c}-0.43(\mathrm{CI}:-0.57 \text { to } \\
-0.26) \mathrm{p}<.0001\end{array}$ & $\begin{array}{l}-0.25 \text { (CI: }-0.38 \text { to } \\
-0.02) \mathrm{p}=0.03\end{array}$ & $\begin{array}{c}-0.09 \text { (CI:-0.27 to } 0.10) \\
\mathrm{p}=0.371^{*}\end{array}$ \\
\hline FM & & $\begin{array}{l}0.72(\mathrm{CI}: 0.62 \text { to } \\
0.08) \mathrm{p}<.0001\end{array}$ & $\begin{array}{c}-0.44(\mathrm{CI}:-0.58 \text { to } \\
-0.26) \mathrm{p}<.0001\end{array}$ & $\begin{array}{l}-0.21(\mathrm{CI}:-0.42 \text { to } \\
-0.07) \mathrm{p}=0.008\end{array}$ & $\begin{array}{c}-0.04 \text { (CI:-0.28 to } 0.21) \\
\mathrm{p}=0.711^{*}\end{array}$ \\
\hline BMI & & $\begin{array}{l}0.81(\mathrm{CI}: 0.73 \text { to } \\
0.87) \mathrm{p}<.0001\end{array}$ & $\begin{array}{l}-0.21(\mathrm{CI}:-0.38 \text { to } \\
-0.03) \mathrm{p}=0.03\end{array}$ & $\begin{array}{l}-0.11 \text { (CI:-0.29 to } \\
0.08) \mathrm{p}=0.254^{*}\end{array}$ & $\begin{array}{c}0.07 \text { (CI:-0.12 to } 0.26 \text { ) } \\
\mathrm{p}=0.452^{*}\end{array}$ \\
\hline \multirow[t]{2}{*}{ Height } & & $\begin{array}{l}0.68(\mathrm{CI}: 0.56 \text { to } \\
0.77) \mathrm{p}<.00001\end{array}$ & $\begin{array}{l}-0.46(\mathrm{CI}:-0.59 \text { to } \\
-0.29) \mathrm{p}<.00001\end{array}$ & $\begin{array}{l}-0.37(\mathrm{CI}:-0.52 \text { to } \\
-0.20) \mathrm{p}<.0001\end{array}$ & $\begin{array}{c}-0.12 \text { (CI:-0.36 to } 0.13 \text { ) } \\
\mathrm{p}=0.205^{*}\end{array}$ \\
\hline & & $\mathrm{VO}_{2} \max$ & $\mathrm{VO}_{2} \max / \mathrm{BM}$ & $\mathrm{VO}_{2} \max / \mathrm{FFM}$ & $\mathrm{VO}_{2} \mathrm{max} / \mathrm{BM}^{-0.69}$ \\
\hline BM & \multirow{6}{*}{ 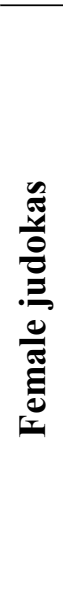 } & $\begin{array}{l}0.82(\mathrm{CI}: 0.76 \text { to } \\
0.88) \mathrm{p}<.0001\end{array}$ & $\begin{array}{l}-0.54(\mathrm{CI}:-0.67 \text { to } \\
-0.40) \mathrm{p}<.0001\end{array}$ & $\begin{array}{l}-0.23 \text { (CI:-0.40 to } \\
-0.04) p=0.015\end{array}$ & $\begin{array}{c}-0.12 \text { (CI:-0.36 to } 0.13 \text { ) } \\
\mathrm{p}=0.203^{*}\end{array}$ \\
\hline$\% \mathrm{BF}$ & & $\begin{array}{l}0.46(\mathrm{CI}: 0.27 \text { to } \\
0.58) \mathrm{p}<.0001\end{array}$ & $\begin{array}{l}-0.58(\mathrm{CI}:-0.69 \text { to } \\
-0.44) \mathrm{p}<.0001\end{array}$ & $\begin{array}{l}-0.04 \text { (CI:- } 0.15 \text { to } \\
0.23) \mathrm{p}=0.679^{*}\end{array}$ & $\begin{array}{c}-0.01 \text { (CI:-0.20 to } 0.18) \\
\mathrm{p}=0.918^{*}\end{array}$ \\
\hline FFM & & $\begin{array}{l}0.84(\mathrm{CI}: 0.78 \text { to } \\
0.89) \mathrm{p}<.0001\end{array}$ & $\begin{array}{l}-0.44(\mathrm{CI}:-0.58 \text { to } \\
-0.27) \mathrm{p}<.0001\end{array}$ & $\begin{array}{c}-0.28 \text { (CI:-0.44 to } \\
0.09) \mathrm{p}=0.004\end{array}$ & $\begin{array}{c}-0.18 \text { (CI:-0.36 to } 0.01) \\
\mathrm{p}=0.062^{*}\end{array}$ \\
\hline FM & & $\begin{array}{c}.62 \text { (CI:0.49to 0.72) } \\
\mathrm{p}<.0001\end{array}$ & $\begin{array}{l}-0.59(\mathrm{CI}:-0.70 \text { to } \\
-0.45) \mathrm{p}<.0001\end{array}$ & $\begin{array}{c}0.005 \text { (CI: }-0.18 \text { to } \\
0.19) \mathrm{p}=0.606^{*}\end{array}$ & $\begin{array}{l}0.09 \text { (CI:-0.1 to } 0.35) \\
\quad \mathrm{p}=0.203^{*}\end{array}$ \\
\hline BMI & & $\begin{array}{l}0.75(\mathrm{CI}: 0.66 \text { to } \\
0.83) \mathrm{p}<.0001\end{array}$ & $\begin{array}{l}-0.53(\mathrm{CI}:-0.65 \text { to } \\
-0.38) \mathrm{p}<.0001\end{array}$ & $\begin{array}{c}-0.10(\mathrm{CI}:-0.34 \text { to } \\
0.14) \mathrm{p}=0.282 *\end{array}$ & $\begin{array}{c}-0.04 \text { (CI:-0.15 to } 0.23 \text { ) } \\
\mathrm{p}=0.679^{*}\end{array}$ \\
\hline Height & & $\begin{array}{l}0.58(\mathrm{CI}: 0.44 \text { to } \\
0.69) \mathrm{p}<.0001\end{array}$ & $\begin{array}{c}-0.34 \text { (CI:-0.49 to } \\
-0.16) \mathrm{p}<.0004\end{array}$ & $\begin{array}{c}-0.23 \text { (CI: }-0.40 \text { to } \\
-0.04) \mathrm{p}=0.015\end{array}$ & $\begin{array}{c}0.04 \text { (CI:-0.15 to } 0.23 \text { ) } \\
\mathrm{p}=0.680^{*}\end{array}$ \\
\hline
\end{tabular}

$B M$ - body mass, \%BF-percent body fat, FM - fat mass, FFM - fat-free mass, BMI - Body mass index, $\mathrm{VO}_{2}$ max - maximal oxygen uptake, $\mathrm{CI}$ - confidential interval, n.s. - not significant $(p<0.05)$

The results statistically showed significant positive correlations between $\mathrm{VO}_{2} \max$ and all tested body composition variables in both sexes. The strength of the association with the weight, FFM and BMI in male judokas were very strong (respectively, $r=0.85, r=0.85$, and $r=0.81$ ), with height and FM - strong (respectively, $r=0.68$, and $r=0.72)$ and with $\% \mathrm{BF}$ - moderate $(r=0.50)$. The results were similar for female judokas very strong associations of $\mathrm{VO}_{2}$ max with the weight $(r=0.82)$ and FFM ( $r=0.84)$, strong with BMI and FM (respectively $r=0.75$ and $r=0.62$ ) and moderate - with height and \%BF (respectively, $r=0.58$, and $r=0.46$ ).
When $\mathrm{VO}_{2}$ max was expressed in relative to $\mathrm{BM}$ terms, the correlations between $\mathrm{VO}_{2}$ max and all body composition variables were negative and moderate except for BMI in male athletes and height in female athletes, where the association was weak. All correlation coefficients were significant at $p<0.05$.

The normalized to FFM values of the $\dot{\mathrm{VO}}_{2}$ max were with weak association with the weight, height, FFM and FM in male judokas, and with weight, height and FFM in female judokas. All other correlation coefficients were statistically insignificant $(p<0.05)$.

There were no significant correlations iden- 
tified between $\mathrm{VO}_{2}$ max. $\mathrm{BM}^{-0.77}$ for male athletes and $\mathrm{VO}_{2}$ max. $\mathrm{BM}^{-0.69}$ for female athletes and body composition variables (Table 2, Figure 2).

The scatterplots (Figure 2) summarize the results of the Pearson product-moment correlations between $\mathrm{VO}_{2}$ max expressed by different methods and body mass in male and
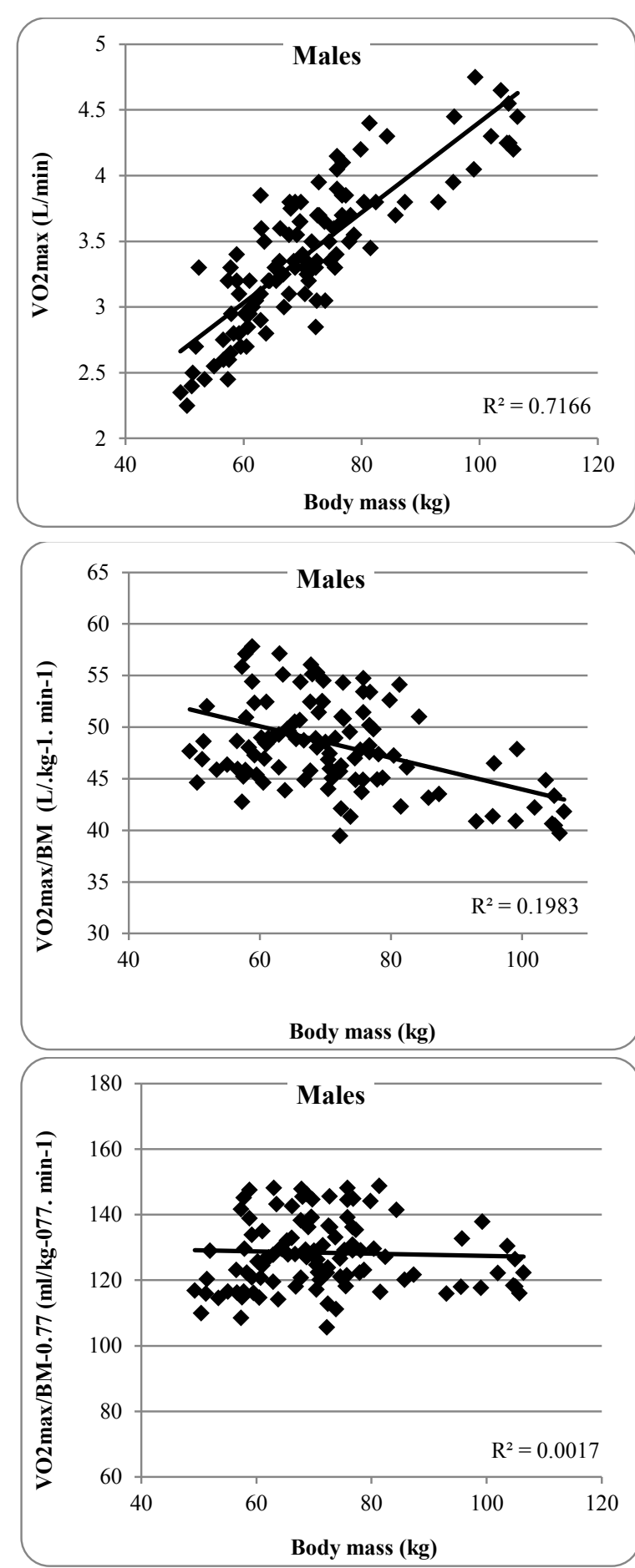

female judokas. Overall, there was a strong, positive correlation between absolute values of $\mathrm{VO}_{2} \max$ and $\mathrm{BM}$; weak, negative correlation between $\mathrm{VO}_{2}$ max expressed as a simple ratio standard and $\mathrm{BM}$; and no correlation between allometric scaled $\mathrm{VO}_{2}$ max and $\mathrm{BM}$ in judokas from both sexes.
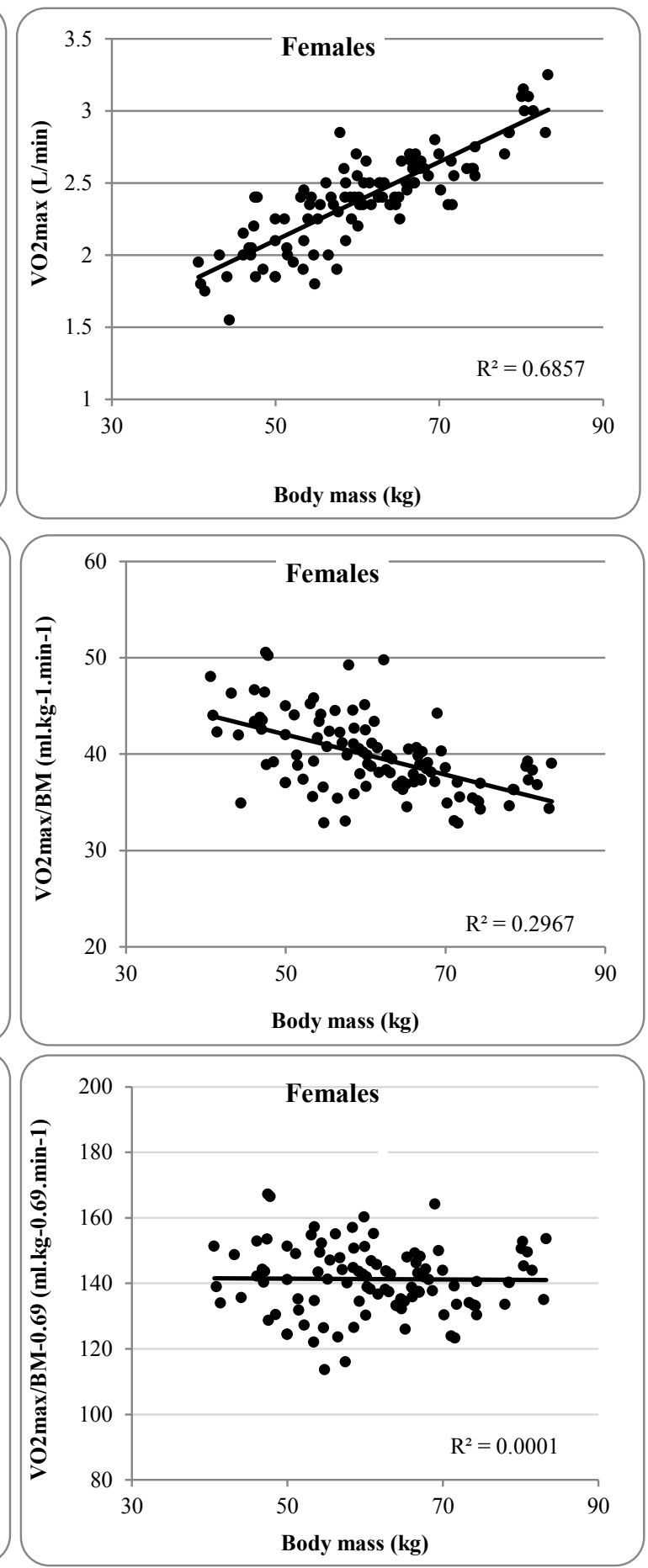

Figure 2. Relationship between absolute $\mathrm{VO}_{2}$ max and body mass, ratio scaled $\mathrm{VO}_{2}$ max and body mass, and power function ratio and body mass in male and female judokas 


\section{DISCUSSION}

The primary objective of this study was to characterize the changes in the body composition and aerobic capacity of judo athletes from both sexes with respect to weight categories.

In this study, the body fat percentage of the entire groups of male and female judokas was not high $-10.6 \% \pm 2.2$ for males and $14.4 \% \pm 5.2$ for females. These values are in accordance with the data from other authors who summarized the results for judo athletes from different nationalities (Franchini et al., 2011a; Torres-Luque et al., 2016). Additionally, it should be noted that these values are significantly lower than those of the general population (Yordanov, 2012). It is well known, that in order to gain a competitive advantage, the judokas try to optimize their body weight so that within the weight category to have more lean tissues and less body fat (Franchini at al., 2014). However, we observed a marked trend for increasing the body fat percentage and the fat free mass along with the increase of the weight category of the competitors. Comparing the results for the three weight categories we found significant differences between them in all body composition variables (height, $\% \mathrm{BF}$, FM, FFM, BMI), with the highest average values in the heaviest athletes from both sexes. These results confirmed the findings by other authors that increased weight of the athletes from heavy-weight categories is due not only to an increase of lean mass but also to a higher adiposity (Franchini, et al., 2014; Stachoń, et al., 2014; Singh, 2015).

Body composition can have considerable implications on performance of aerobic and anaerobic tasks. The maximal oxygen uptake reflects the maximum capacity to transport and utilize oxygen and is generally considered as the best single marker of the functional capacity of the aerobic system (Shephard, 1994). Various studies suggest that aerobic capacity is influenced by changes in body size. In this study, the mean values for absolute $\mathrm{VO}_{2} \max$, increased with the body weight of the athletes from 3.14 L.min ${ }^{-1}$ for the lightweight group to $4.30 \mathrm{~L} \cdot \mathrm{min}^{-1}$ for the heavyweight group of males, and respectively, from $2.09 \mathrm{~L} \cdot \mathrm{min}^{-1}$ to 2.77 L. $\mathrm{min}^{-1}$ for the females. The highest values of $\mathrm{VO}_{2} \max (p<0.05)$, reached at the end of the incremental test, by the heavyweights, simply reflected their greater body mass.

Since the absolute value of the $\mathrm{VO}_{2}$ max is highly affected by the body mass, it is generally accepted to express aerobic capacity in relative units (with a denominator $\mathrm{BM}^{-1}$ ). The average $\mathrm{VO}_{2}$ max. $\mathrm{BM}^{-1}$ of the entire groups of male and female judokas were respectively $48.4 \pm 4.7 \mathrm{ml} \cdot \mathrm{kg}^{-1} \cdot \mathrm{min}^{-1}$ and $39.7 \pm 4.0 \mathrm{ml} \cdot \mathrm{kg}^{-1}$. $\min ^{-1}$. These values approximate to the lower limit of aerobic capacity, reported for judo players from other nationalities (Franchini, 2011a) and are closer to those of the general population than to those of endurance athletes.

When compared the relative to body mass values of $\mathrm{VO}_{2} \max$, the lightweight categories were with the highest results and the heavyweight athletes were with the lowest results in both gender groups of judokas and the significant differences $(p<0.05)$ between weight categories in male and female athletes were still apparent.

This result is in accordance with the data, presented by other authors (Franchini et al., 2007, Thomas et al., 1989) and may suggest that the heavier judo contestants have lower aerobic performance or otherwise, high BM, regardless of body composition, has a negative effect on the relative aerobic capacity. However, such statement is misleading and has been criticized by a number of authors, who found that the simple ratio standard favored lighter individuals and penalized those with larger BM (Katch, Katch, 1974; Winter et al., 1991; Vanderburgh, Katch, 1998; Welsman et al. 1996). 
The secondary objective of this study was to assess how the body size of male and female judo players from different weight categories affects their aerobic capacity by examining different approaches for scaling the maximal oxygen uptake.

As was already mentioned, there is a range of evidence to suggest that $\mathrm{VO}_{2}$ max is affected by the body composition (Mondal, Mishra, 2017; Hunt et al., 1998; Goran et al., 2000). Accordingly, when expressing $\mathrm{VO}_{2}$ max per $\mathrm{kg}$ $\mathrm{BM}$, the results of the athletes who compete in lightweight category were the highest, indicating that they have a higher aerobic capacity compared to other categories. However, the correlation analysis still demonstrated moderate negative associations between $\mathrm{VO}_{2}$ max. $\mathrm{BM}^{-1}$ and all body composition variables. Hence, using the conventional method of expression of $\mathrm{VO}_{2} \max$ the results for the different groups are not independent of the body mass. This is in accordance with the existing statement that the use of whole-body mass as scaling denominator for $\mathrm{VO}_{2}$ max does not remove the confounding effect of body size (Nevill, 1994; Svedenhag, 1995; Heil, 1997). Although the theoretical and statistical limitations of the simple ratio standard have been well-documented, its use in the exercise science still remains common.

One of the factors explaining the significant differences in absolute oxygen uptake among groups of athletes with different BM, is the considerable heterogeneity of body composition (Lolli et al., 2016). Traditionally, sports scientists use the two-compartment model of body composition, which divides the body into two chemically distinct compartments - the fat mass and fat-free mass. A larger part of FFM constitute the muscle mass. The $\mathrm{VO}_{2} \max$ is strongly influenced by the total active muscle mass being gained during exercise, as the skeletal muscle mass is the greatest consumer of oxygen during exercise (Tolfrey et al., 2006; Toth et al., 1994; Hunt et al., 1998). Therefore, it is reasonable to expect that the variability in the FFM may account for the differences in the $\mathrm{VO}_{2} \max$. In this sense, some authors consider the FFM is more appropriate scaling denominator for $\mathrm{VO}_{2}$ max than is $\mathrm{BM}$ (Toth et al., 1994; Hunt et al., 1993, Goran et al., 2000).

In the present study, the aerobic capacity of the male judokas, adjusted for the differences in the FFM, was with significantly highest values $(p<0.05)$ for the lightweight category and lowest for the heavyweight category. The correction of $\mathrm{VO}_{2}$ max for the FFM eliminated the differences between the three weight categories in female judokas, and they demonstrated similar results.

However, weak and negative, but significant correlations between $\mathrm{VO}_{2}$ max/FFM, body mass, fat-free mass and fat mass were found in males. In females, similar relationships were observed between $\mathrm{VO}_{2}$ max/FFM and the body mass and fat-free mass.

It is assumed that the allometric scaling allows for examining the maximal oxygen uptake that remove the confounding effect of the body mass (Nevill et al, 1992, 2003; Welsman et al., 1996; Lolli et al., 2016).

The theory using 2/3of the individual's body mass as scaling factor is based on the surface to volume relationship in Euclidean geometry and dated back to the 19th century. According to surface law, the exponent in the allometric relationship between $\mathrm{VO}_{2}$ max and body mass should be 0.67 . However, almost two centuries later McMahon, using the concept of elasticity, proposed that body surface area increases as volume ${ }^{3 / 4}$ rather than volume ${ }^{2 / 3}$. Nevertheless, recent studies have established that in athletic and non-athletic population the experimentally derived scaling factors may deviate from the theoretical exponents. In a systematic review involving a large sample of 7,851 participants 
Lolli et al. (2016) estimated the pooled allometric exponent $(95 \% \mathrm{CL})$ to be $0.71(0.65$ to 0.77 ) for body mass. Jensen et al. (2001) analyzed data for 655 male and 312 female athletes from 25 different sports and found an allometric exponent of 0.73 .

In this study, using log-linear analysis of covariance with body mass as the covariate, we determined sex-specific body mass exponents for use in the power function scaling. The experimentally derived exponent for males (0.77) was significantly higher than that for females (0.69) $(p<0.0001)$.

The 95\% CI of both sex-specific BM exponents were lower than $1.0 \quad(p<0.0001)$, suggesting that the relationship between the $\mathrm{VO}_{2}$ max and $\mathrm{BM}$ is curvilinear as well as the increase in oxygen consumption is faster than the increase in weight in both sexes. The derived mass exponents were consistent with the theoretically predicted by $2 / 3$ and $3 / 4$ power law (Heil, 1997; Nevill, 1994; Svedenhag, 1995). For female judokas the scaling factor is close to the $2 / 3$ law, but for males it is closer to $3 / 4$ law. According to Heil (1997), the differences in size exponents may reflect the heterogeneity of the studied samples with respect to age, training background, and height.

Using power function modelling for scaling the $\mathrm{VO}_{2}$ max Chia \& Aziz (2008) revealed also different allometric factors for both sexes - $b=0.67$ for male athletes and $b=0.24$ for female athletes. The results of Lolli et al. (2016) demonstrated lower exponent in women ( $b=0.52 ; 95 \%$ CL: 0.41 to 0.64$)$ than for men ( $b=0.77$; 95\% CL: 0.71 to 0.83 ).

In this study, the use of the allometric scaling factor to normalize the $\mathrm{VO}_{2}$ max produced similar results for the three weight categories in both sexes of judokas, without significant differences between them $(p<0.05)$. This result suggests that the differences in the body size and composition of the judokas compet- ing in different weight categories did not affect their aerobic capacity. Moreover, no residual correlations were found between $\mathrm{VO}_{2}$ max/ $\mathrm{BM}^{0.77(0.69)}$ and all body composition variables, which confirms the appropriateness of the allometric scaling as an efficient method for correction of differences in body size between weight categories in judo.

To the best of our knowledge this is the first study characterizing the aerobic capacity of judo contestants with respect to the weight categories by using different methods of normalization for the body size. The results may help both in characterization of the differences between the weight categories in judo and in better understanding the variations in the aerobic power in judo contestants.

\section{Limitations}

It is important to emphasize that all body composition variables in this study were derived based on prediction equations using skinfold thickness. The mean error of prediction equations, as it is recognized, can vary between 3 and $6 \%$.

Another limitation is that the study encompassed individuals in wide age range, and due to the relatively small number of subjects in the individual weight groups, the study did not take into account their maturational status. No data were received regarding the menstrual cycle phase of female athletes.

Also, the maximal oxygen uptake test was performed on a cycle ergometer and the values would not be applicable if the test was to be performed with the use of other ergometers such as a treadmill.

\section{CONCLUSION}

The body composition variables, such as height, weight, \%BF, FM and FFM increase along with increasing the weight category. The absolute values of the $\mathrm{VO}_{2}$ max are highest in 
heavy-weight category, followed by middleweight and light-weight ones. However, based on the results of this study, it can be concluded that the interpretation of the aerobic capacity in judokas with different body size is dependent on the method of the expression of $\mathrm{VO}_{2}$ max. The normalized to BM and FFM values of $\mathrm{VO}_{2}$ max by ratio standard were still in correlation with body composition variables, therefore the highest results for light-weighted athletes were misleading. In contrast, the power function expression of $\mathrm{VO}_{2}$ max produced size-free variable in male and female judo players. The allometric scaling of the aerobic capacity in both sexes showed similar results for the three weight categories, regardless of the differences in their body composition. This study provides a better understanding of the association between aerobic capacity and body size in judokas that is useful for coaches and sports scientists.

\section{ACKNOWLEDGMENTS}

The authors would like to thank the athletes for their kind participation in this study. No funding was used in conducting the study.

\section{REFERENCE}

Ali, P.N., Hanachi, P., Nejad, N.R. (2010). The relation of body fats, anthropometric factor and physiological functions of Iranian female national judo team. Modern Applied Science, Vol. 4 No. 6, pp. 25-29.

Åstrand, P-0. (1952). Experimental studies of physical working capacity in relation to sex and age. E. Munksgaard, Copenhagen, pp. 103-115.

Borkowsky, L., Faff, J., Starczewska-Czapowska, J. (2001). Evaluation of the aerobic and anaerobic fitness in judoists from the Polish national team. Biology of Sport, Vol. 18 No. 2, pp. 107-111.

Callister, R., Callister, R.J., Saron, R.S., Fleck, S.J., Tesch, P., Dudley, G.A. (1991). Physiological characteristics of elite judo athletes. International Journal of Sports Medicine, Vol. 12
No. 2, pp. 196-203.

Chia, M., Aziz, A.R. (2008). Modelling Maximal Oxygen Uptake in Athletes: Allometric scaling versus ratio-scaling in relation to body mass. Annals of Academy of Medicine of Singapore, Vol. 37 No. 4, pp. 300-306.

Cureton, K., Bishop, P., Hutchinson, P., Newland, H., Vickery, S., Zwiren, L. (1986). Sex difference in maximal oxygen uptake. Effect of equating haemoglobin concentration. European Journal of Applied Physiology and Occupational Physiology, Vol. 54 No. 6, pp. 656-660.

Fletcher, G.F., Ades, P.A., Kligfield, P., Arena, R., et al. (2013). Exercise Standards for Testing and Training. A Scientific Statement from the American Heart Association. Circulation, Vol.128 No. 8, pp. 873-934.

Franchini, E., Artioli, G.G., Brito, C.J. (2013). Judo combat: Time-motion analysis and physiology. International Journal of Performance Analysis in Sport, Vol. 13 No. 2, pp. 624-641.

Franchini, E., Bertuzzi, R.C., Takito, M.Y., Perduti Dal'Molin Kiss, M.A. (2009). Effects of recovery type after judo match on blood lactate and performance in specific and non-specific judo tasks. European Journal of Applied Physiology, Vol. 107, No. 4, pp. 377-383.

Franchini, E., Del Vecchio, F.B., Matsushigue, K.A, Artioli, G.G. (2011a). Physiological profiles of elite judo athletes. Sports Medicine, Vol. 41 No.2, pp. 147-166.

Franchini, E., Nunes, A.V., Moraes, J.M., Del Vecchio, F.B. (2007). Physical fitness and anthropometrical profile of the Brazilian male judo team. Journal of Physiological Anthropology, Vol. 26 No.2, pp. 59-67.

Franchini, E., Sterkowicz- Przybycien K., Takito, M.Y. (2014). Anthropometrical profile of judo athletes: Comparative analysis between weight categories. International Journal of Morphology, Vol. 32 No.1, pp. 36-42.

Franchini, E., Sterkowicz, S., Szmatlan-Gabrys, U., Gabrys, T., Garnys, M. (2011b). Energy System Contributions to the Special Judo Fitness Test. International Journal of Sport Physioliology, Vol. 6 No. 3, pp. 334-343.

Franchini, E., Takito, M.Y., Kiss, M.A.P.D.M., Sterkowicz, S. (2005). Physical fitness and anthropometrical differences between elite and 
non-elite judo players. Biology of Sport, Vol. 22, No. 4, pp. 315-328.

Goran, M., Fields, D.A., Hunter, G.R., Herd, S L, Weinsier R.L. (2000). Total body fat does not influence maximal aerobic capacity. International Journal of Obesity, Vol. 24 No.7, pp. 841-848.

Heil, D.P. (1997). Body mass scaling of peak oxygen uptake in 20- to 79-yr-old adults. Medicine and Science in Sports and Exercise, Vol. 29 No.12, pp. 1602-1608.

Hunt, B.E., Davy, K.P., Jones, P.P., DeSouza, C.A., Van Pelt, R.E., Tanaka, H., Seals, D.R. (1998). Role of central circulatory factors in the fat-free mass-maximal aerobic capacity relation across age. American Journal of Physiology, Vol. 275 No. 4 Pt 2, pp. H1178-1182.

Jackson, A.S., Pollock, M.L. (1978). Generalized equations for predicting body density of men. British Journal of Nutrition, Vol. 40 No. 3, pp. 497-504.

Jackson, A.S., Pollock, M.L. (1985). Practical assessment of body-composition. The Physician and Sports Medicine, Vol. 13 No. 5, pp. 6-90.

Jackson, A.S., Pollock, M.L., Ward,A. (1980). Generalized equations for predicting body density of women. Medicine and Science in Sports and Exercise, Vol. 12 No.3, pp. 175-181.

Jensen, K., Johansen, L., Secher, N.H. (2001). Influence of body mass on maximal oxygen uptake: effect of sample size. European Journal of Applied Physiology, Vol. 84 No. 3, pp. 201-205.

Katch, V.L. and Katch, F.I. (1974). Use of weight-adjusted oxygen uptake scores that avoid spurious correlations. Research Quarterly, Vol. 45 No. 4, pp. 447-451.

Kim, J., Cho, H.C., Jung, H.S., Yoon, J.D. (2011). Influence of performance level on anaerobic power and body composition in elite male judoists. Journal of Strength and Conditioning Research, Vol. 25 No. 5, pp. 1346-1354.

Kubo, J., Chishaki, T., Nakamura, N., Muramatsu, T., Yamamoto, Y., Ito, M., Saitou, H., Kukidome, T. (2006). Differences in fat-free mass and muscle thicknesses at various sites according to performance level among judo athletes. Journal of Strength and Condition Research, Vol. 20 No. 3, pp. 654-657.

Little, N.G. (1991). Physical performance attributes of junior and senior women, juvenile, junior and senior men judokas. Journal of Sports Medicine and Physical Fitness, Vol. 31 No. 4, pp. 510-520.

Lolli, L., Batterham, A.M., Weston, K., Atkinson, G. (2016). Size-exponents for scaling maximal oxygen uptake in over 6500 humans: a systematic review and meta-analysis. British Journal of Sports Medicine. Vol. 50 No. 22, pp. e4.12-e14.

Maciejczyk, M., Więcek, M., Szymura, J., Szyguła, Z., Wiecha, S., Cempla, J. (2014). The influence of increased body fat or lean body mass on aerobic performance. PLoS One, Vol. 9 No.4, pp. e95797.

Marfell-Jones, M., Olds, T., Stewart, A., Carter, L. (2006). International standards for anthropometric assessment. Potchefstroom, South Africa: ISAK.

Mondal, H. and Mishra, S.P. (2017). Effect of BMI, Body Fat Percentage and Fat Free Mass on Maximal Oxygen Consumption in Healthy Young Adults. Journal of Clinical and Diagnostic Research, Vol. 11 No.1, pp. CC17-CC20.

Nevill, A., Brown, D., Godfrey, R., Johnson, P., Romer, L., Stewart, A. D, Winter, E. M. (2003). Modeling maximum oxygen uptake of elite endurance athletes. Medicine and Science of Sports and Exercise, Vol. 35 No. 3, pp. 488-494.

Nevill, A.M. (1994). The need to scale for differences in body size and mass: an explanation of Kleiber's 0.75 mass exponent. Journal of Applied Physiology, Vol. 77 No. 6, pp. 2870-2873.

Nevill, A.M., Ramsbottom, R., Williams, C. (1992). Scaling physiological measurements for individuals of different body size. European Journal of Applied Physiology. Vol. 65, No. 2, pp. 110-117.

Nikolova A., Dimitrova D. (2018). Morphological characteristics of judo cadets with respect to sex-related differences and athletic achievements. Biomedical Human Kinetics, Vol. 10 No.1, pp. 169-177.

Perez-Gomez, J.G. V. Rodriguez, Ara, I., Olmedillas, H., Chavarren, J., González-Henriquez, J.J., Dorado, C., Calbet, J.A. (2008). Role of muscle mass on sprint performance: gender differences? European Journal of Applied Physiology, Vol. 102 No. 6, pp. 685-694.

Shephard, R.J. (1994). Aerobic fitness and health. Human Kinetics Publ., Champaign, Ill. 
Singh, P. (2015). Study of body composition among university level judo players in relation to different weight categories. International Journal of Advanced Research, Vol. 3, No. 10, pp. 1052-1056.

Siri, W.E. (1961). Body composition from fluid space and density. In J. Brozek, A. Henschel (Eds). Techniques for Measuring Body Composition, pp. 223-241. Washington, DC: National Academy of Science.

Sparling, P.B. (1980). A meta-analysis of studies comparing maximal oxygen uptake in men and women. Research Quarterly for Exercise and Sport, Vol. 51 No. 3, pp. 542-552.

Stachoń, A., Pietraszewska, J., Burdukiewicz, A., Andrzejewska, J. (2014). The diversity of body composition, body proportions and strength abilities of female judokas in different weight categories. Archives of Budo, Vol. 10 No. 1, pp. 37-46.

Sterkowicz, S., Zuchowicz, A., Kubica, R. (1999). Levels of anaerobic and aerobic capacity indices and results for the special judo fitness test in judo competitors. Journal of Human Kinetics, Vol. 21 No. 2, pp. 115-135.

Sterkowicz-Przybycień, K., Almansba, R. (2011). Sexual dimorphism of anthropometrical measurements in judoists vs untrained subject. Science \& Sports, Vol. 26 No. 6, pp. 316-323.

Svedenhag, J. (1995). Maximal and submaximal oxygen uptake during running: how should body mass be accounted for? Scandinavian Journal of Medicine and Science in Sports, Vol. 5 No. 4, pp. 175-180.

Thomas, S.G., Cox, M.H., LeGal, Y.M., et al. (1989). Physiological profiles of the Canadian National Judo Team. Canadian Journal of Sport Science, Vol. 14, No.3, pp. 142-147.

Tolfrey, K., Barker, A., Thom, J.M., Morse,
C.I., Narici, M.V., Batterham, A.M. (2006). Scaling of Maximal Oxygen Uptake by Lower Leg Muscle Volume in Boys and Men. Journal of Applied Physiology, Vol. 100, No. 6, pp. 1851-1856.

Torres-Luque, G., Hernanez-Garcia, R. Escobaar-Molina, R., Garatacea, N., Nikolaidis, P.T. (2016). Physical and physiological characteristics of judo athletes: An update. Sports, Vol. 4 No. 1, pp. 20-31.

Toth, M.J., Gardner, A.W., Ades, P.A., Poehlman, E.T. (1994). Contribution of body composition and physical activity to age-related decline in peak V O2 in men and women. Journal of Applied Physiology, Vol. 77, No. 2, pp. 647-652.

Toth, M.J., Goran, M.I., Ades, P.A., et al. (1993). Examination of data normalization procedures for expressing peak VO2 data. Journal of Applied Physiology, Vol. 75 No. 5, pp. 2288-2292.

Vanderburgh, P. and Katch, F. (1996). Ratio scaling of $\dot{\mathrm{V} O} 2 \mathrm{max}$ penalize women with larger percent body fat, not lean body mass. Medicine and Science in Sports and Exercise, Vol. 28, No. 9, pp. 1204-1208.

Welsman, J.R., Armstrong, N., Nevill, A.M., Winter, E.M., Kirby, B.J. (1996). Scaling peak VO2 for differences in body size. Medicine and Science in Sports and Exercise, Vol. 28 No.2, pp. 259-265.

Winter, E.M., Brookes, F.B.C., Hamley, E.J. (1991). Maximal exercise performance and lean leg volume in men and women. Journal of Sports Science, Vol. 9 No. 1, pp. 3-13.

Yordanov, Y. ed. (2012). Physical development of children and youths in Bulgaria on the borderline between $20^{\text {th }}$ and $21^{\text {st }}$ century. Prof. Marin Drinov Academic Publishing House, Sofia.

\section{Corresponding author:}

Diana Dimitrova
Department of "Sports medicine"
National Sports Academy "Vassil Levski"
21, Acad. Stefan Mladenov Str.
Sofia 1700, Bulgaria
E-mail: dianansa@yahoo.com

